\title{
Modelling chemo-hydro-mechanical behaviour of unsaturated clays: a feasibility study
}

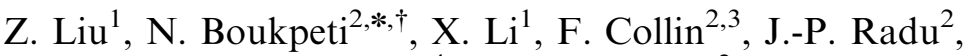 \\ T. Hueckel ${ }^{4}$ and R. Charlier ${ }^{2}$ \\ ${ }^{1}$ The State Key Laboratory for Structural Analysis of Industrial Equipment, Dalian University of Technology, China \\ ${ }^{2}$ Department GeomaC, University of Liege, Belgium \\ ${ }^{3}$ FNRS Post-doctoral Researcher, Belgium \\ ${ }^{4}$ Department of Civil and Environmental Engineering, Duke University, Durham, NC, U.S.A.
}

\begin{abstract}
SUMMARY
Effective capabilities of combined chemo-elasto-plastic and unsaturated soil models to simulate chemohydro-mechanical (CHM) behaviour of clays are examined in numerical simulations through selected boundary value problems. The objective is to investigate the feasibility of approaching such complex material behaviour numerically by combining two existing models. The chemo-mechanical effects are described using the concept of chemical softening consisting of reduction of the pre-consolidation pressure proposed originally by Hueckel (Can. Geotech. J. 1992; 29:1071-1086; Int. J. Numer. Anal. Methods Geomech. 1997; 21:43-72). An additional chemical softening mechanism is considered, consisting in a decrease of cohesion with an increase in contaminant concentration. The influence of partial saturation on the constitutive behaviour is modelled following Barcelona basic model (BBM) formulation (Géotech. 1990; 40(3):405-430; Can. Geotech. J. 1992; 29:1013-1032).

The equilibrium equations combined with the CHM constitutive relations, and the governing equations for flow of fluids and contaminant transport, are solved numerically using finite element. The emphasis is laid on understanding the role that the individual chemical effects such as chemo-elastic swelling, or chemo-plastic consolidation, or finally, chemical loss of cohesion have in the overall response of the soil mass. The numerical problems analysed concern the chemical effects in response to wetting of a clay specimen with an organic liquid in rigid wall consolidometer, during biaxial loading up to failure, and in response to fresh water influx during tunnel excavation in swelling clay. Copyright (C) 2005 John Wiley \& Sons, Ltd.
\end{abstract}

KEY WORDS: plasticity; chemical softening; unsaturated soil; constitutive models; swelling clays; tunnelling

\footnotetext{
*Correspondence to: N. Boukpeti, Universite Catholique de Louvain, Batiment Vinci, place du Levant 1, B-1348

Louvain la Neuve, Belgium.

${ }^{\dagger}$ E-mail: boukpeti@gce.ucl.ac.be

Contract/grant sponsor: Ministry of Education; contract/grant number: ARC No. 99/04-243

Contract/grant sponsor: Fonds National de la Recherche Scientifique

Contract/grant sponsor: The National Natural Science Foundation; contract/grant number: 50278012

Contract/grant sponsor: The National Natural Science Foundation; contract/grant number: 59878009
}

Received 11 May 2004

Copyright (C) 2005 John Wiley \& Sons, Ltd.

Revised 28 March 2005

Accepted 31 March 2005 


\section{INTRODUCTION}

It has been recognized that the presence of certain chemicals in the pore fluid of clayey soils affects their hydro-mechanical behaviour, whereas a change in pore fluid can induce deformation. Understanding the chemical aspects of clay behaviour is essential for the design of clay barriers against chemical or nuclear contaminants, as well as for ensuring tunnel or borehole stability in expansive soils. In some cases, like the storage of nuclear waste, chemical effects have to be considered in combination with the effects of temperature and partial saturation. Swelling or contractive strains have been measured in clay permeated with organic liquids, depending on the chemical concentration and the stress level [1]. Compaction or swelling of clay upon exposure to changes in pore water salinity have been widely reported and explained by the osmotic effect. It has been shown that part of these strains are irreversible [2]. If swelling is prevented, substantial swelling pressure develops. At a constant load, there is a partial swelling depending on the load. Also, it has been observed that swollen clay has a much reduced strength $[3,4]$.

Several constitutive models have been suggested to describe the chemo-mechanical behaviour of clays in various environmental circumstances. For example, the modelling concepts proposed by Hueckel [5] and Hueckel et al. [6] account for phenomena occurring at three different scales: nano, micro and macro. However, using the framework of plasticity it is possible to represent the macroscopic behaviour of clays in a phenomenological manner. Within this framework, the concept of chemical softening was suggested by Hueckel [7] to describe strains occurring in clay due to the change in the pore fluid dielectric constant or ionic concentration due to contamination by a single chemical. Using a similar concept, Nova et al. [8] developed an elastoplastic strain-hardening model for chemical degradation of bonded geomaterials. Guimaraes et al. [9] proposed a model for expansive clays, which describes the effects of changes in ionic solutions on the microstructure and the macrostructure of the clay, as well as the interactions between the two scales. Olivella and Gens [10] modelled the effect of dissolution of crystal grain contact in salt gem.

The formulation employed in this paper is based on the chemo-plasticity theory proposed by Hueckel [5, 7]. It is assumed that as the mass concentration of a generic contaminating species increases in the pore fluid the elastic domain and hence the yield surface shrink (chemical softening). Within the elastic domain, chemical effects include chemo-elastic expansive strain, also a function of the mass concentration, whereas at state of plastic yielding chemo-plastic compaction takes place. The same concepts were used in the model presented by Boukpeti et al. [11]. In the current formulation, an additional chemical effect is included, which is the decrease of the cohesion with chemical concentration. It is assumed that the two chemical softening mechanisms are due solely to changes in physico-chemical properties of the pore fluid. Due to these changes, the arrangement of the clay particles may change (e.g. flocculation) or the thickness of the adsorbed water layer may vary, leading to some swelling/shrinkage of the soil and to some evolution of its mechanical properties (see for example Reference [12]). The cases of contamination involving chemical reactions, dissolution or precipitation processes are not addressed in the present work.

It is believed that in most real life situations, soil sub-saturation and chemical contamination affect the same properties of soils. To study these combined effects, the chemo-mechanical model described before is incorporated into a model of the behaviour of unsaturated soils derived by Collin [13] and Collin et al. [14]. The latter model follows the Barcelona basic model 


\section{MODELLING CHEMO-HYDRO-MECHANICAL BEHAVIOUR}

(BBM) formulation $[15,16]$, which considers the effects of suction (difference between air and water pressure) on the compression coefficient, pre-consolidation pressure, and cohesion. The yield surface is composed of an elliptical cap, a frictional-failure locus and a tension limit. The variations of suction and chemical concentration influence the size of the elliptical cap via the pre-consolidation pressure and the position of the frictional-failure line via the cohesion.

In the following section, the constitutive equations for the chemo-hydro-mechanical (CHM) behaviour of unsaturated clays are presented. The other governing equations are the equilibrium equations, and the governing equations for fluid flow and mass transport of contaminant, which are described in Section 3. Next, three numerical examples are discussed. The first problem consists of a test of wetting of an initially unsaturated clay specimen with an organic contaminant, the second is a biaxial compression test with a concomitant injection of a chemical, and the third problem simulates an excavation in clay followed by a permeation of pure water in the rock mass with an originally mineralized pore water. The numerical simulations were performed using the finite element program LAGAMINE [17].

\section{CONSTITUTIVE MODEL}

\subsection{Basic assumptions for modelling chemical effects}

The constitutive model presented in the next subsection aims at describing chemical effects on the mechanical behaviour of clays. These chemical effects can be caused by the action of dissolved cations, or organic liquids in low concentration, and also by the presence of (nearly) pure water entering in contact with a clay mass containing ionized pore water. The proposed formulation is quite general and can be adapted to solve specific applications.

The intensity of chemical contamination is measured by the mass concentration, defined as the ratio of mass of the chemical to the total mass of fluid, normalized against a reference value $(c \leqslant 1)$. The mass concentration can be expressed in the form

$$
c=\frac{m_{c} / m_{f}}{c_{\text {ref }}}
$$

where $m_{c}$ is the mass of the chemical, $m_{f}$ the total mass of fluid, and $c_{\text {ref }}$ is a reference value.

In some cases, like for example invasion of a clay mass by fresh water, the definition of chemical concentration has to be adapted in order to be incorporated in the proposed framework. In this case, the concentration of ions is lower in fresh water than in the clay pore water, therefore, it is proposed to use pure water as the species to characterize the chemical effects and its concentration in the pore solution as the chemical variable. As clearly pure water heavily dominates the solution, the concentration variable needs to be appropriately normalized to make the concentration changes numerically meaningful and in the range between zero and one. Hence, it is proposed to define concentration $c$ as

$$
c=\frac{c_{w p, x t}-c_{w r}}{c_{w f}-c_{w r}}
$$

where $c_{w p, x t}$ is a current variable concentration of pure water in pore solution of ions and water, $c_{w f}$ is a reference concentration of pure water in fresh water solution of ions and water, and $c_{w r}$ is a reference concentration of pure water in rock pore water solution of ions and water. Clearly, $c_{w f}>c_{w r}$. Introducing the total concentration of ions and all other minerals dissolved in rock 
natural pore water solution, $c_{i r}$, in fresh water solution, $c_{i f}$, and in current pore solution, $c_{i p, x t}$, Equation (2) can be rewritten as

$$
c=\frac{c_{i r}-c_{i p, x t}}{c_{i r}-c_{i f}}
$$

A typical value of $c_{i r}$ for a homoionic sodium montmorillonite is $c_{i r}=1200 \times 10^{-6}$, whereas typically $c_{i f}=100 \times 10^{-6}$ for fresh water.

\subsection{General formulation}

The constitutive equations, expressed in a rate form, relate the strain tensor, $\varepsilon_{i j}$, to the stress tensor, $\sigma_{i j}$, suction, $s$, and mass concentration of a chemical, $c$. A positive strain corresponds to compaction. The suction is defined by the difference between the air and water pressure $(s \geqslant 0)$. In the formulation given below, the stress tensor designates alternatively the net stress (difference between total stress and air pressure), in the case of unsaturated conditions, or the effective stress in the case of full saturation. The strain rate is decomposed into an elastic (reversible) part and a plastic (irreversible) part. The elastic part can also be decomposed into mechanical, suction, and chemical contributions, namely

$$
\dot{\varepsilon}_{i j}=\dot{\varepsilon}_{i j}^{e}+\dot{\varepsilon}_{i j}^{p}=\dot{\varepsilon}_{i j}^{e, m}+\dot{\varepsilon}_{i j}^{e, s}+\dot{\varepsilon}_{i j}^{e, c}+\dot{\varepsilon}_{i j}^{p}
$$

The plastic deformation occurs when the yield condition in terms of appropriate stress is reached. Notably, plastic strain rate can be generated by variations in suction, or concentration, at constant stress state.

The mechanical elastic stress-strain law is adopted in a classical form as

$$
\dot{\sigma}_{k l}=C_{k l i j}^{e} \dot{\varepsilon}_{i j}^{m, e}
$$

with the compliance elastic tensor $C_{k l i j}^{e}$ defined as

$$
C_{k l i j}^{e}=2 G \delta_{i k} \delta_{j l}+\left[\frac{(1+e)}{3 \kappa} \sigma_{m m}-\frac{2}{3} G\right] \delta_{i j} \delta_{k l}
$$

where $\delta_{i j}$ is Kronecker delta tensor, $G$ is the elastic shear modulus, $e$ is the void ratio and $\kappa$ is the elastic bulk modulus (logarithmic).

The elastic strain rate induced by suction change is adopted after BBM [15] as

$$
\dot{\varepsilon}_{i j}^{s, e}=\frac{1}{3} \frac{\kappa_{s}}{(1+e)} \frac{\dot{s}}{\left(s+p_{a t}\right)} \delta_{i j}=h_{i j}^{e} \dot{s}
$$

where $p_{a t}$ is the atmospheric pressure and $\kappa_{s}$ is the elastic compressibility parameter for changes in suction. As depicted in Figure 1, this isotropic deformation is contractive for an increase in suction $s$ (drying) and expansive for a decrease of $s$ (wetting). Analogous to the mechanical volumetric strain in Cam clay model, it is a logarithmic relationship.

The reversible chemical strain is also assumed as isotropic and is written in the form

$$
\dot{\varepsilon}_{i j}^{c, e}=-\frac{1}{3} \beta \dot{c} \delta_{i j}=l_{i j}^{e} \dot{c}
$$

where a specific form of the chemical expansion coefficient, function $\beta$, is adopted from Hueckel [7] as

$$
\beta=-F_{0} \beta_{0} \exp \left[\beta_{0}(1-c+\ln c)\right]\left(\frac{1}{c}-1\right)
$$




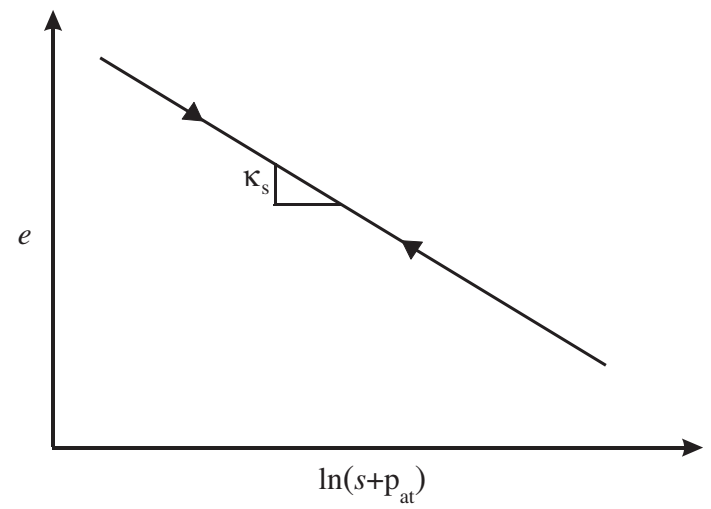

Figure 1. Elastic volumetric response to suction loading and unloading.

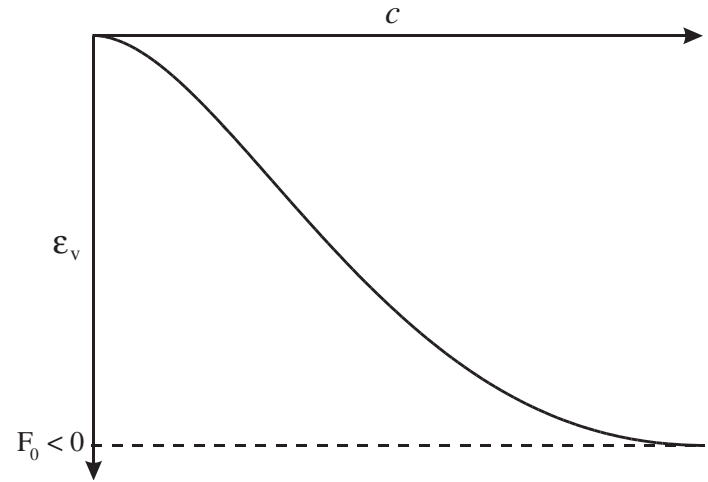

Figure 2. Elastic volumetric response to an increase in chemical concentration.

where $F_{0}$ and $\beta_{0}$ are material constants dependent on the soil and the chemical. The relation between concentration and chemo-elastic volumetric strain is illustrated in Figure 2. This type of relationship implies an asymptotically reached limit for the chemical expansion.

The plastic strain rate is described within the framework of strain-hardening/softening plasticity. The yield criterion reads

$$
f\left(\sigma_{i j}, \theta\right) \leqslant 0
$$

where $\theta$ is an internal variable depending on plastic strain, suction and concentration. During plastic loading, the yield function $f$ needs to satisfy the consistency condition

$$
\dot{f}=\frac{\partial f}{\partial \sigma_{i j}} \dot{\sigma}_{i j}+\frac{\partial f}{\partial \theta} \dot{\theta}=0
$$

The evolution of the internal variable $\theta$ is described by a hardening/softening law

$$
\dot{\theta}=\frac{\partial \theta}{\partial \varepsilon^{p}} \dot{\varepsilon}^{p}+\frac{\partial \theta}{\partial s} \dot{s}+\frac{\partial \theta}{\partial c} \dot{c}
$$


In the present model, only the volumetric component of the plastic strain rate is considered in the hardening law. The plastic strain rate vector is defined by the non-associated flow rule

$$
\dot{\varepsilon}_{i j}^{p}=\dot{\Lambda}^{p} \frac{\partial g}{\partial \sigma_{i j}}
$$

where $g$ is the plastic potential and $\dot{\Lambda}^{p}$ is the plastic multiplier. The general form of the constitutive equations relating the stress increment to the increments of strain, suction and concentration is derived in Appendix A.

\subsection{Plastic behaviour}

Three plastic yielding mechanisms are considered: pore collapse or plastic deformation with volumetric compaction, frictional-cohesive failure with possible dilation, and tensile failure. These three mechanisms are represented by the three following yield criteria:

$$
\begin{gathered}
f_{1}=q^{2}+M^{2}\left(p+p_{s}\right)\left(p-p_{0}\right)=0, \quad p \geqslant\left(p_{0}-p_{s}\right) / 2 \\
f_{2}=q-M\left(p+p_{s}\right)=0, \quad \sigma_{t}<p \leqslant\left(p_{0}-p_{s}\right) / 2 \\
f_{3}=p+\sigma_{t}=0
\end{gathered}
$$

where $p_{0}$ is the pre-consolidation pressure, $p_{s}$ is a parameter which can be related to the cohesion $\left(p_{s} \geqslant 0\right), M$ is a parameter defining the slope of the frictional-cohesive failure locus, and $\sigma_{t}$ is the tensile strength. The stress invariants $p$ and $q$ are defined as: $p=\sigma_{k k} / 3$ and $q=\sqrt{3 / 2 s_{i j} s_{i j}}$, where $s_{i j}$ is the deviatoric part of the stress tensor. In the stress plane $(q, p), f_{1}$ represents an ellipse with intercepts on the $p$-axis $\left(-p_{s}\right)$ and $p_{0}$ (see Figure 3 ). The yield function $f_{2}$ represents a straight line of slope $M$ and an intercept on the $p$-axis at $\left(-p_{s}\right)$. The parameter $M$ is a function of the Lode angle according to the formulation of Van Eekelen [18]. As a result the yield surface in the deviatoric plane is a smoothed hexagon coinciding with the Mohr-Coulomb surface for

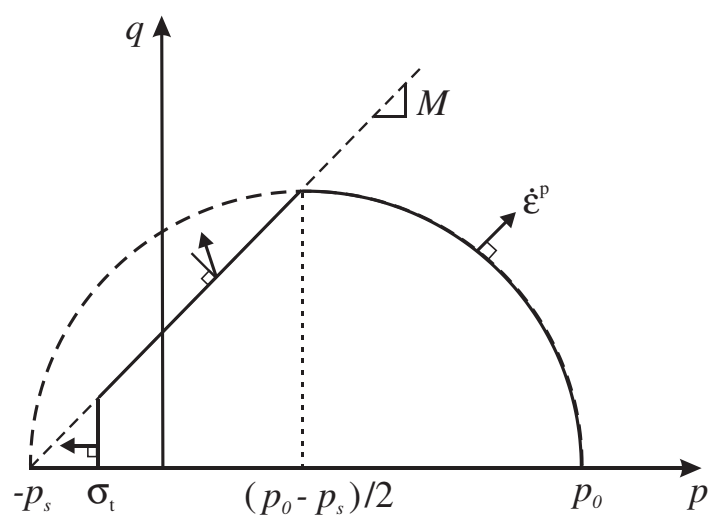

Figure 3. Yield surface in the stress plane $(q, p)$. 
triaxial compression and triaxial extension. The failure line (15) and ellipse (14) intersect at the vertex of the ellipse, i.e. at $p=\left(p_{0}-p_{s}\right) / 2$. The tensile failure criterion $f_{3}=0$ is represented as a vertical line in Figure 3. The tensile yielding is modelled via an associated flow rule and no hardening.

The hardening/softening rules for the pore collapse model and the frictional-cohesive failure model are described below. For the physical and phenomenological motivation of the specific functions, see the original references.

2.3.1. Hardening/softening rule for pore collapse model. The pore collapse model is based on the Cam clay model; the yield surface $f_{1}$ is elliptical, the flow rule is associated, and the internal variable $p_{0}$ evolves with the volumetric component of the plastic strain. The effects of suction and concentration on the internal variable $p_{0}$ are described by

$$
p_{0}(s, c)=p_{c} S(c)\left(\frac{p_{0}^{*}}{p_{c}}\right)^{(\lambda(0)-\kappa) /(\lambda(s)-\kappa)}
$$

where $p_{c}$ is a reference pressure, $p_{0}^{*}$ is the pre-consolidation pressure for $s=0$ and $c=0$, and $\lambda(0)$ is the compression coefficient at zero suction. The compression coefficient $\lambda(s)$ is a decreasing function of $s$

$$
\lambda(s)=\lambda(0)\left[(1-r) \exp \left(-\beta^{\prime} s\right)+r\right]
$$

where $0<r<1$ is a constant related to the maximum stiffness of clay (at infinite suction) and $\beta^{\prime}$ is a constant controlling the stiffness increase (decrease of $\lambda$ ) with suction increase, as defined in BBM model [15]. According to Equation (17), the pre-consolidation pressure increases with an increase in suction, as depicted in Figure 4(a). The evolution of $p_{0}$ with suction defines the loading-collapse (LC) line, which limits the domain of elastic swelling from the domain of plastic pore collapse.

The chemical softening function $S(c)$ is adopted in the form proposed by Hueckel [7]

$$
S(c)=\exp (-a c)
$$

where $a$ is a constant governing the decrease of the pre-consolidation pressure $p_{0}$ with an increase in concentration. This is represented by the chemical softening (CHS) line in

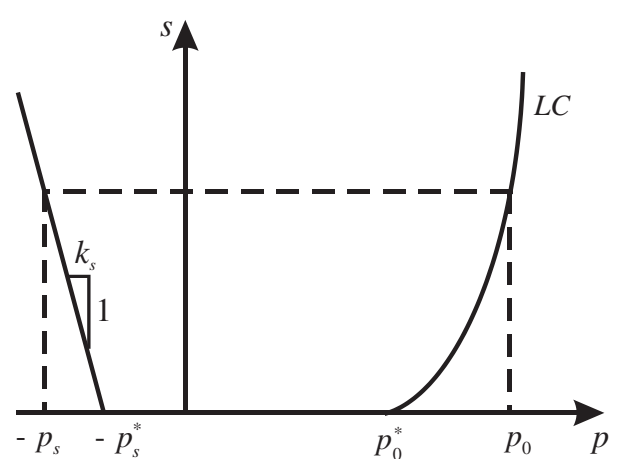

(a)

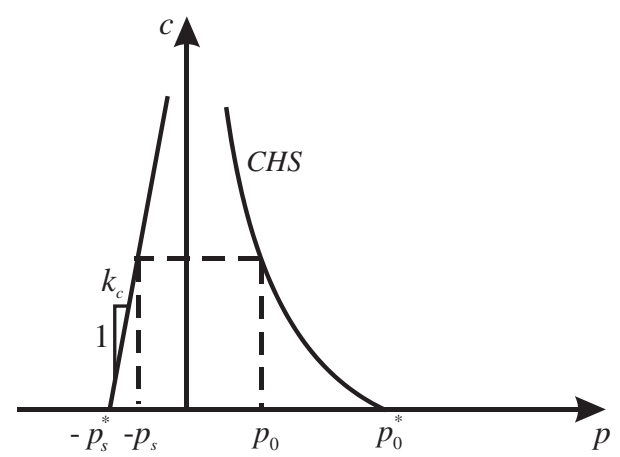

(b)

Figure 4. Yield surface: (a) in the plane $(s, p)$; and (b) in the plane $(c, p)$. 
Figure 4(b). The evolution of $p_{0}^{*}$ follows a volumetric hardening law

$$
\dot{p}_{0}^{*}=\frac{1+e}{\lambda-\kappa} p_{0}^{*} \dot{\varepsilon}_{v}^{p}
$$

2.3.2. Frictional-cohesive failure model. Frictional-cohesive failure takes place when the state of stress lies on the yield surface $f_{2}$. Plastic strains obey a non-associated flow rule with the plastic potential defined as

$$
g_{2}=q-M^{\prime}\left(p+p_{r}\right)=0
$$

where $M^{\prime}$ is a parameter controlling the dilatancy, and $p_{r}$ is determined from the requirement that the stress point lies on $g_{2}$. The influence of the Lode angle on $M^{\prime}$ is described by the formulation of Van Eekelen [18]. The internal variable $p_{s}$ in Equation (15), which is related to the cohesion, is assumed to evolve as a linear function of suction and concentration, namely

$$
p_{s}=p_{s}^{*}+k_{s} s+k_{c} c
$$

where $k_{s}\left(k_{s} \geqslant 0\right)$ and $k_{c}\left(k_{c} \leqslant 0\right)$ are constants, and $p_{s}^{*}$ is the value of the parameter $p_{s}$ for saturated conditions $(s=0)$ and at chemically neutral conditions $(c=0)$. This type of hardening law for the effect of suction was proposed in the BBM model [15]. We propose also to use a linear law to describe chemical effects on parameter $p_{s}$. The hardening-softening law (22) is illustrated in Figure 4.

\section{FLUID AND CHEMICAL TRANSPORT MODELS}

\subsection{Fluid transport}

The fluid flow formulation accounts for unsaturated conditions as described by Collin et al. [14]. However, in the present paper the flow of air is neglected (i.e. the air pressure is constant). The water volume flux, $f_{w}$, is governed by a generalized Darcy's law

$$
\left.\underline{f_{w}}=-\frac{k_{r w} k_{\text {int }}^{\text {sat }}}{\mu} \underline{\operatorname{grad}}\left(p_{w}\right)+g \rho_{w} \underline{\operatorname{grad}(y)}\right]
$$

where $p_{w}$ is the water pressure, $\rho_{w}$ is the water density, $g$ is the acceleration of gravity, $y$ is the vertical upward directed co-ordinate, $k_{\text {int }}^{\text {sat }}$ is the intrinsic permeability of the medium, and $k_{r w}$ is the relative water permeability, which varies with the saturation degree. In this paper, the variation of relative permeability with saturation degree follows the works of Brooks and Corey [19], and is described by

$$
k_{r w}=\frac{\left(S_{r w}-S_{\mathrm{res}}\right)^{3}}{\left(S_{r \text { field }}-S_{\mathrm{res}}\right)^{3}}
$$

where $S_{r w}$ is the saturation degree, $S_{\text {res }}$ is the residual saturation and $S_{r \text { field }}$ is the natural field saturation. The flow of water is constrained by the mass balance law, which reads

$$
\frac{\partial}{\partial t}\left(\rho_{w} n S_{r w}\right)+\operatorname{div}\left(\rho_{w} \underline{f_{w}}\right)=0
$$




\section{MODELLING CHEMO-HYDRO-MECHANICAL BEHAVIOUR}

where $n$ is the porosity. The expression for the retention curve is taken after Vauclin et al. [20] as

$$
S_{r w}=S_{\text {res }}+\frac{\left(S_{r \text { field }}-S_{\text {res }}\right) A}{A+(C * s)^{B}}
$$

where $A, B$, and $C$ are constants.

\subsection{Chemical mass transport}

The chemical mass transport model is based on the assumption of a very low concentration of the chemical species. In this condition, the fluid flow is not affected by the contaminant. Three main processes are considered in the model: advection of the species with the fluid average velocity, mechanical dispersion due to local variations of the flow velocity, and molecular diffusion of the species driven by the gradient of its concentration. The effects of chemical reactions, adsorption, degradation, exchange with immobile water, dissolution, precipitation, and other forms of mass loss or gain are not considered in the present model (for a description of some of these effects and the corresponding sink/source terms in the governing equations, see References [21,22]).

The flux of chemical species due to molecular diffusion is governed by Fick's law

$$
\underline{f_{c}}=-d_{m} \nabla\left(n S_{r w} c\right)
$$

where $d_{m}$ is the coefficient of molecular diffusion. Similarly, the flux due to mechanical dispersion is represented by a diffusion law

$$
\underline{f_{d}}=-D \nabla\left(n S_{r w} c\right)
$$

where $D$ is the mechanical dispersion tensor, expressed in terms of the longitudinal and transversal dispersion coefficients. The mass balance of the species reads

$$
\frac{\partial}{\partial t}\left(n S_{r w} c\right)+\operatorname{div}\left(\underline{c} \underline{f_{w}}+\underline{f_{c}}+\underline{f_{d}}\right)=0
$$

Note that for simplicity, the influence of mechanical dispersion is disregarded in the examples presented in the next section.

\section{BOUNDARY VALUE PROBLEMS: BENCHMARK STUDIES}

In this section we present and discuss results of finite element based studies of a series of boundary value problems, where chemical and variable saturation effects are coupled. As our objective is a feasibility study, our focus is on investigating how the components of the model

describing different aspects of clay response to change in the environmental conditions affect the overall clay mass behaviour.

\subsection{Chemical effects on clay behaviour during wetting by a contaminant}

To investigate the combined effects of chemical and suction on the behaviour of clay, a representative wetting test was modelled, where the wetting fluid interacts chemically with the clay. In such a test, a cylindrical clay specimen of $2 \mathrm{~cm}$ thickness is placed in a rigid wall consolidometer, in which it deforms only vertically (see Figure 5). Initially, an external vertical 


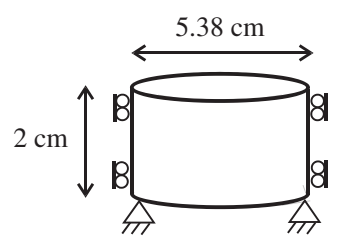

Initial conditions: $\sigma_{\mathrm{v}}=133 \mathrm{kPa}$ $s=78.6 \mathrm{MPa}$ $c=0.0$

(a)

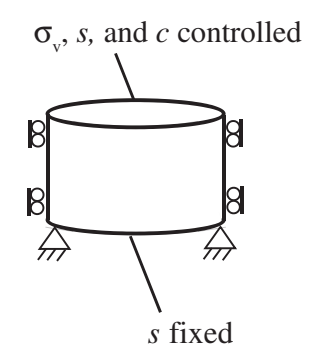

(b)

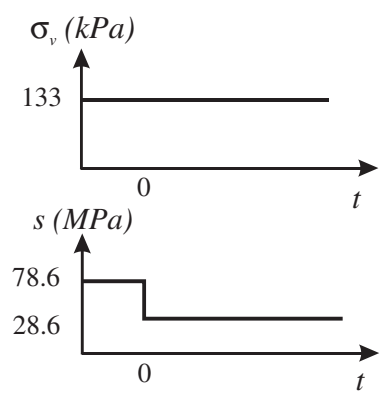

(c)

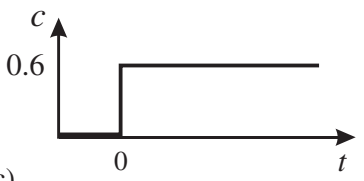

Figure 5. Model of uniaxial wetting test: (a) geometry and initial conditions; (b) boundary conditions; and (c) loading applied on the upper boundary.

load $\sigma_{v}=133 \mathrm{kPa}$ is applied to the specimen, and the horizontal stress is taken as $\sigma_{h}=83 \mathrm{kPa}$ $\left(K_{0}=0.625\right)$. The air pressure is equal to the atmospheric pressure, $p_{a}=100 \mathrm{kPa}$, and is assumed constant during the test. The initial suction is $s=78.6 \mathrm{MPa}$, which corresponds to a saturation degree $S_{r w}=0.49$. The chemical mass concentration is defined by Equation (1) with $c_{\text {ref }}=1 \%$. The initial concentration of the contaminant is zero. The wetting test is modelled by decreasing the suction at the higher end of the specimen to $s=28.6 \mathrm{MPa}$, while increasing the chemical concentration also at the top of the specimen to $c=0.6$ (see Figure 5(c)). The suction remains fixed at the lower end, while the concentration is allowed to vary.

The CHM behaviour of the clay is represented by 'typical' parameters, taken from the literature, and listed in Table I. In particular, the suction parameters and the constants defining the retention and the permeability curves (see Equations (26) and (24)) are taken from Reference [13], and are representative of the behaviour of a bentonite. The chemical parameters are chosen within the range of values determined by Hueckel [7] to model the interactions of clay with organic liquids (ethanol and dioxine) as tested in the experiments by Fernandez and Quigley [1]. To highlight the various possible responses of the model, two values of the pre-consolidation pressure $p_{0}^{*}$ are considered, $p_{0}^{*}=1000$ and $0.2 \mathrm{MPa}$.

As a reference, the solution of the wetting test without any chemical effect has been computed. The decrease of the suction from the initial value to the final distribution shown in Figure 6(a), results in an expansion of the specimen, as depicted in Figure 7 (circles). Identical responses are obtained for the two values of pre-consolidation pressure; in both cases the response remains elastic.

Figure 6(b) depicts the evolution of the concentration distribution with time, when the wetting test is performed with the chemical. Note that the slightly negative values obtained at early time are due to the numerical integration scheme and are not physical. Chemical equilibrium is reached after relatively large time lapse $(\sim 3 \mathrm{~h})$. Figure 7 shows two different types of volumetric response depending on the value of the pre-consolidation pressure $p_{0}^{*}$. The graphs refer to the end of the process at time $t=11000 \mathrm{~s}$. 

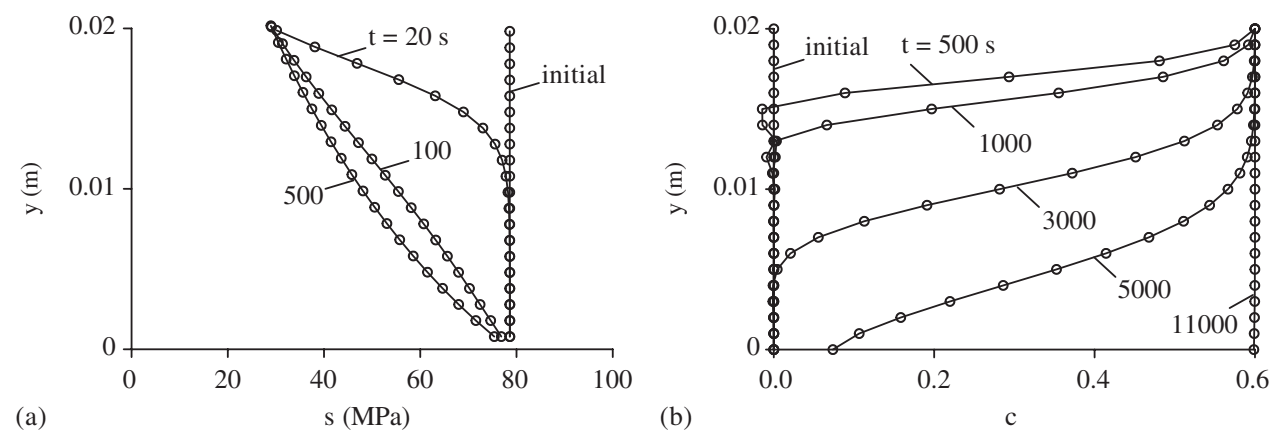

Figure 6. Response to wetting test: (a) evolution of suction distribution; and (b) evolution of chemical concentration distribution.

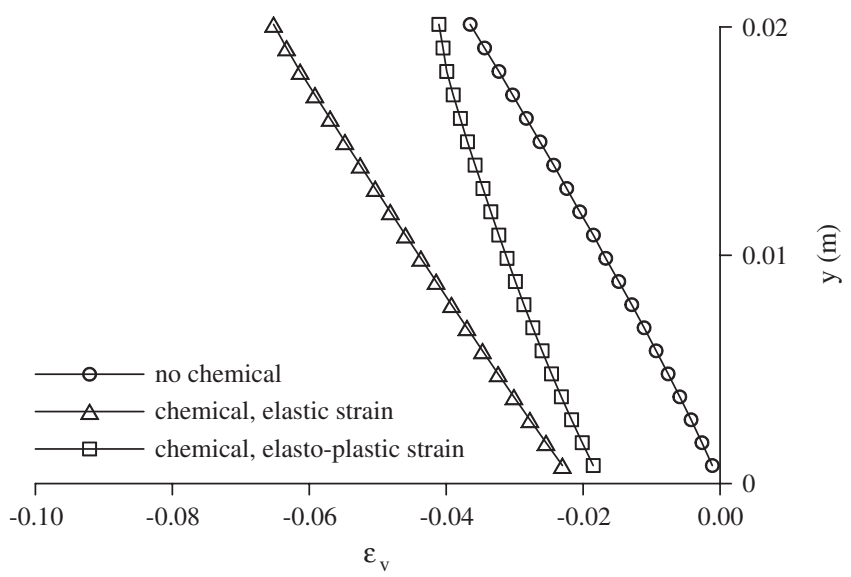

Figure 7. Chemical effects on the volumetric response to wetting.

For the largest value of $p_{0}^{*}, p_{0}^{*}=1000 \mathrm{MPa}$, a nearly uniform chemical expansion is predicted (triangles in Figure 7), in addition to the swelling due to a decrease in suction. The loading path (AB) and the evolution of the parameter $p_{0}$ (dashed line) in the plane $(s, p)$ and the plane $(c, p)$ are depicted schematically in Figures 8(a) and (b). In this case the state of the material remains in the elastic domain. Note that chemical swelling is constrained by the imposed vertical load, leading to an increase in isotropic stress.

For the smallest value of $p_{0}^{*}, p_{0}^{*}=0.2 \mathrm{MPa}$, the chemical effects are not uniform (squares in Figure 7). In this case, plastic states are reached due to chemical softening (decrease of $p_{0}$ ), as shown in Figures 8(c) and (d). Therefore, chemical compaction takes place. Note that the choice of parameters leads to plastic contractive strain being less than the elastic expansive strain. Figure $8(\mathrm{~d})$ shows the plastic yielding point $\mathrm{Y}$ on the loading path $(\mathrm{AB})$, and the distance $\mathrm{YB}$ represents a measure of plastic strain. The plastic strain is higher in the region of smaller suction (lower value of $p_{0}^{C}$, see Figures $8(\mathrm{c})$ and (d)), i.e. at the top of the specimen. This result clearly demonstrates the possibility to model the history effect in coupling between suction and contamination. 


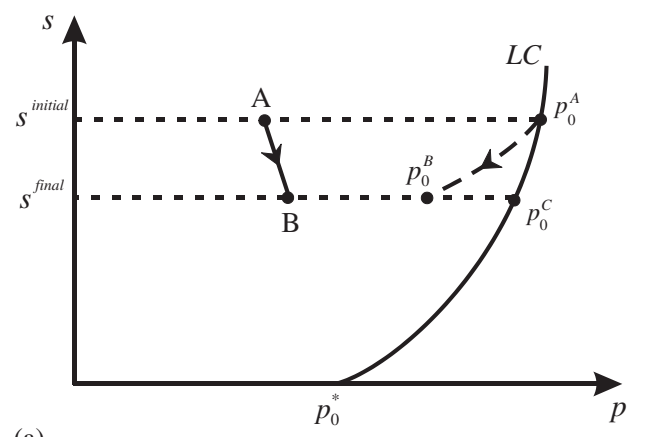

(a)

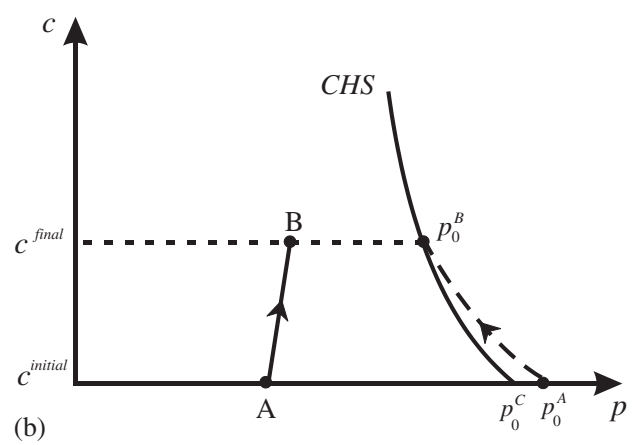

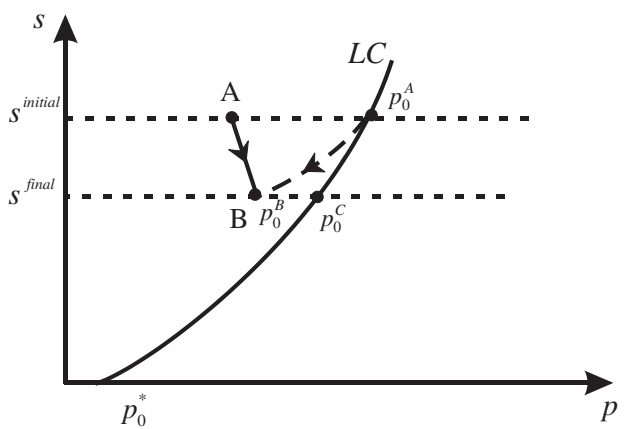

(c)

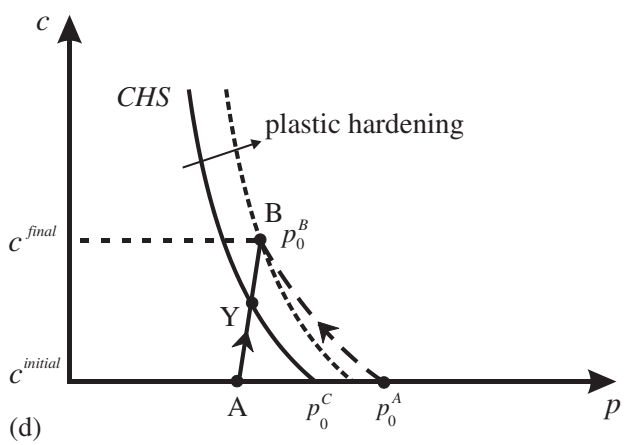

Figure 8. Loading path and evolution of $p_{0}$; for elastic response: (a) plane $(s, p)$; (b) plane $(c, p)$; for elastoplastic response: (c) plane $(s, p)$; and (d) plane $(c, p)$.

\subsection{Chemical effects on biaxial response}

In this simulation, we analyse the chemical effects on the failure of a clay specimen in biaxial loading. The schematic of the biaxial test is shown in Figure 9. The specimen, $10 \mathrm{~cm} \times 17 \mathrm{~cm}$, is compressed between two rigid rough plates with a velocity $v=10^{-6} \mathrm{~m} / \mathrm{s}$ applied to the upper plate, while a constant lateral pressure of $133 \mathrm{kPa}$ is applied. The clay is assumed to be unsaturated with an initial suction $s=78.6 \mathrm{MPa}$. A condition of no drainage is imposed on the boundaries of the specimen. Two notches have been inserted at the top of the specimen to trigger the onset of localized deformation. No chemical is present initially. The hydromechanical parameters representing the behaviour of the clay are listed in Table II. The suction and the chemical parameters are the same as in the previous example (see Table I). The global axial stress-strain response of the clay specimen to biaxial loading is represented by a continuously increasing axial stress (see Figure 10). As the maximum axial stress is reached, failure is initiated by the generation of shear bands (the post-failure response was not analysed).

To model the chemical effects, it is assumed that at some stage of the loading process, the concentration, as defined by Equation (1), increases uniformly throughout the specimen from zero to the maximum value of $c=0.6$, with a rate of $1.5 \times 10^{-4} \mathrm{~s}^{-1}$. As a consequence of the contamination, the stress-strain curve departs from the response obtained in the absence of any chemical, and exhibits a lower maximum followed by a softening part. Figure 11 depicts the deformed mesh, the volumetric strain contours and the flow velocity vectors at an axial strain of 


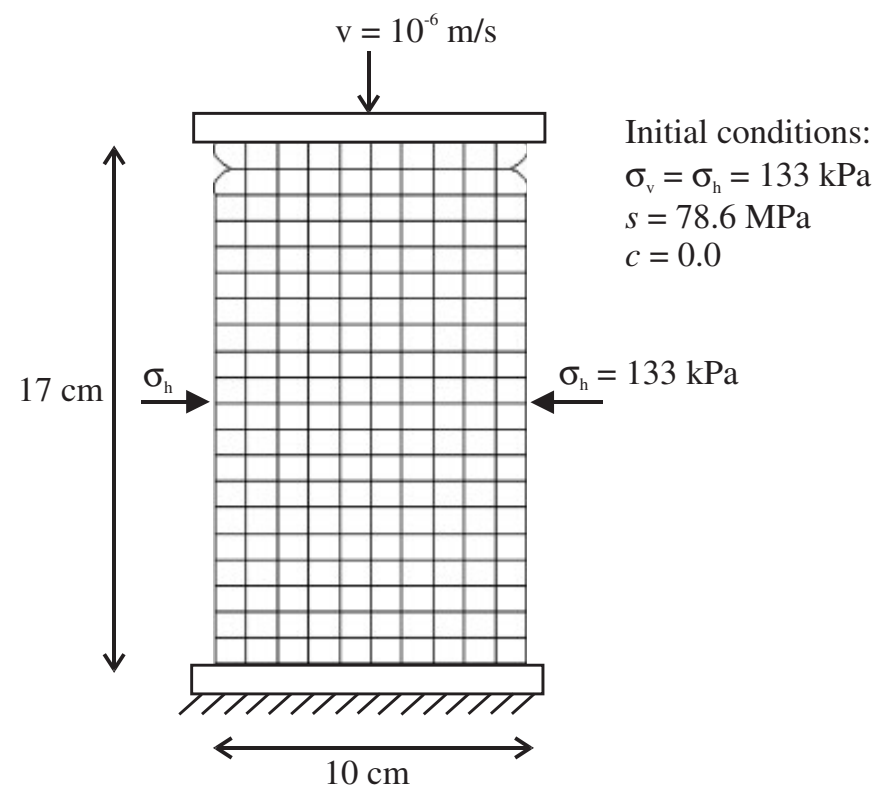

Figure 9. Model of biaxial test.

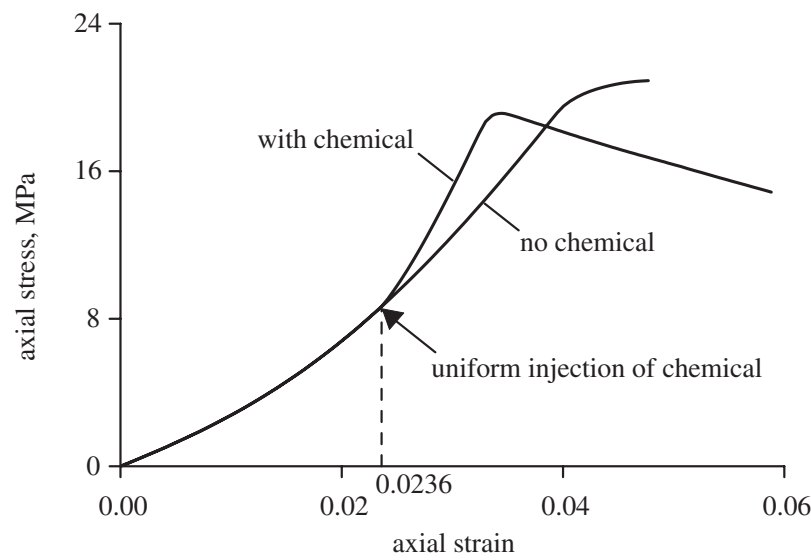

Figure 10. Chemical effects on the biaxial response.

0.06. It appears clearly that the failure of the specimen occurs with the formation of shear bands, which are dilatant, and towards which the fluid flow is directed. Prior to failure, the axial stress in the specimen with chemical is higher than in the specimen without chemical. This is explained by the tendency of the material to expand due to chemo-elastic effects, which is opposed by the controlled displacement. The chemical softening of the cohesion, modelled by a decrease of the parameter $p_{s}$ (controlled by the parameter $k_{c}$ ), has an effect on the maximum axial stress sustained by the specimen and on the type of post-failure response. 


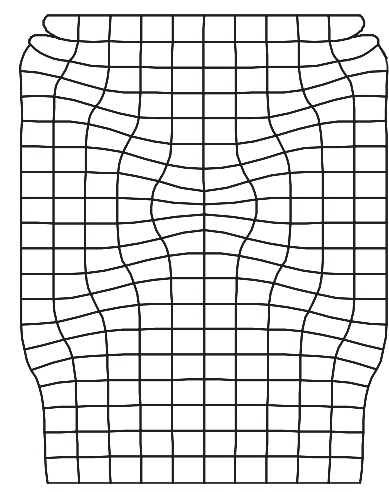

(a)

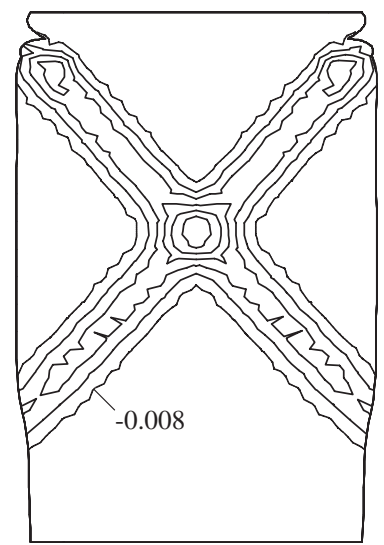

(b)

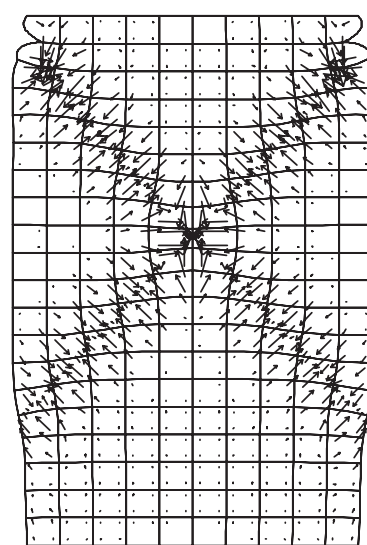

(c)

Figure 11. Biaxial response: (a) deformed mesh (amplification factor of 2); (b) volumetric strain contours (interval of -0.008 ); and (c) water flow velocity vectors (maximum of $6 \times 10^{-9} \mathrm{~m} / \mathrm{s}$ ).

\subsection{Chemical effects around an excavation in clay}

In the last boundary value problem, we analyse chemical effects on the behaviour of a tunnel excavated in clay. We consider a circular tunnel of $5 \mathrm{~m}$ diameter at $220 \mathrm{~m}$ depth in unsaturated clay. The chemical effect consists in the clay mass originally with a highly $\mathrm{Na}^{+}$-ionized pore water entering in contact with fresh water of low salinity. Such effects are notorious to cause swelling of clay and catastrophic heave of tunnel floors and walls [23]. To model these effects, we assume that fresh water is transported from the tunnel's boundary into the clay mass by molecular diffusion. This means that we do not consider any fluid flow at the tunnel's boundary.

The problem is formulated as geometrically symmetrical and is represented by the schematic in Figure 12. An area of $100 \mathrm{~m} \times 100 \mathrm{~m}$ is discretized with a mesh becoming finer near the tunnel. With the soil initial apparent density of $1816 \mathrm{~kg} / \mathrm{m}^{3}$ and the acceleration of gravity taken as $10 \mathrm{~m} / \mathrm{s}^{2}$, the net stress in the soil at the depth of the tunnel's centre is $3.89 \mathrm{MPa}$, both in the vertical and horizontal directions $\left(K_{0}=1\right)$. The initial pore pressure distribution is in equilibrium under gravity, with $p_{w}=-78.5 \mathrm{MPa}$ at the upper boundary of the model (this corresponds to a saturation degree $S_{r w}=0.49$ ). The air pressure is fixed at $p_{a}=100 \mathrm{kPa}$.

The boundary conditions are depicted in Figure 12. Normal stresses are applied on the upper and left boundaries, whereas zero displacements are imposed in the horizontal direction and in the vertical direction, for the right and lower boundaries, respectively. The tunnel's boundary is considered to be undrained, i.e. we consider that the air relative humidity is such that no significant suction is exerted at the tunnels' boundary. However, drainage is allowed on the other boundaries except along the axis of symmetry. The excavation is modelled by reducing the normal stress applied to the tunnel from its initial value to the atmospheric pressure in five steps of $1000 \mathrm{~s}$.

The chemical interaction between fresh water and the clay mass is modelled by using definition (3) for the chemical mass concentration. The initial and boundary conditions for the current concentration of ions in pore solution, $c_{i p, x t}$, at the tunnel perimeter $(x=a)$ are as 


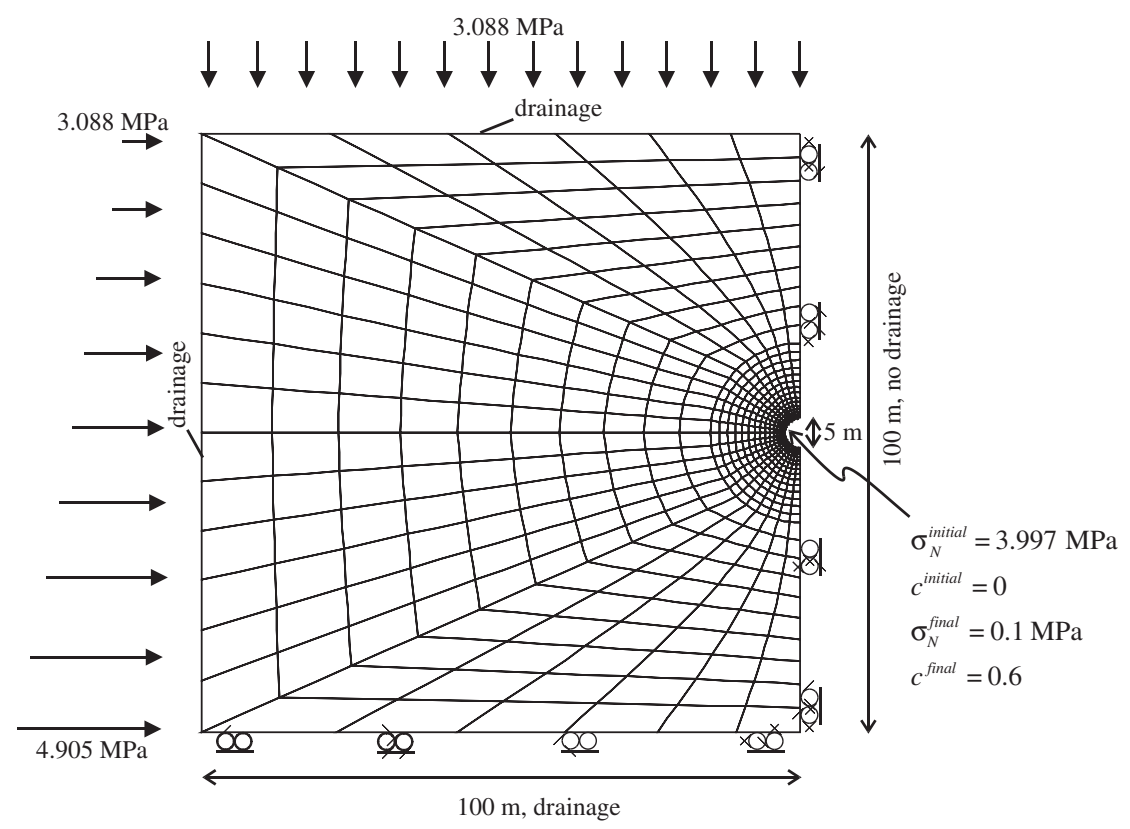

Figure 12. Model of an excavation.

follows:

$$
\begin{gathered}
t=0^{-}, \quad c_{i p, a 0^{-}}=c_{i r} \\
t=0^{+}, \quad c_{i p, a 0^{+}}=\gamma c_{i f}
\end{gathered}
$$

where $\gamma \geqslant 1$ is a process parameter. In this study the value of the process parameter $\gamma$ has been chosen as $\gamma=5.5$, which corresponds to a value of concentration imposed at the tunnel perimeter of $c=0.6$. Note that the value of $\gamma=1.0$ corresponds to $c=1.0$ and represents the maximal chemical effects obtained in the case of invasion of reference fresh water, i.e. containing the minimal amount of ions and dissolved minerals. The boundary condition $c=0.6$ is applied at a rate of $3 \times 10^{-5} \mathrm{~s}^{-1}$.

The hydro-mechanical behaviour of the clay is represented using the parameters of Table III. The parameters characterizing the influence of suction and the chemo-mechanical coupling are the same as in the first example (see Table I). Two cases are analysed; one with a large value of $p_{0}^{*}=1000 \mathrm{MPa}$, for which only chemical elastic expansion takes place, and the second one with a smaller value of $p_{0}^{*}=2 \mathrm{MPa}$, leading to the development of a plastic region around the tunnel.

The loading paths and variations of pre-consolidation pressure $p_{0}$ are represented schematically in Figure 13 for the two cases. The path $\mathrm{AB}$ corresponds to the excavation, and the path $\mathrm{BC}$ to the chemical effects. The actual initial value of pre-consolidation pressure $p_{0}^{A}$ is larger than $p_{0}^{*}$ due to the influence of initial suction (Figure 13(b)). The increase of isotropic stress during the chemical phase is due to the constrain imposed on the material during chemical elastic swelling. For the case with $p_{0}^{*}=2 \mathrm{MPa}$, plastic yielding occurs for the pore collapse model in some region around the tunnel (see Figure 13(d)). To simplify the schematic of Figure 13(f), a vertical path was represented after the yield point Y. However, the stresses may still vary 
Z. LIU ET $A L$.
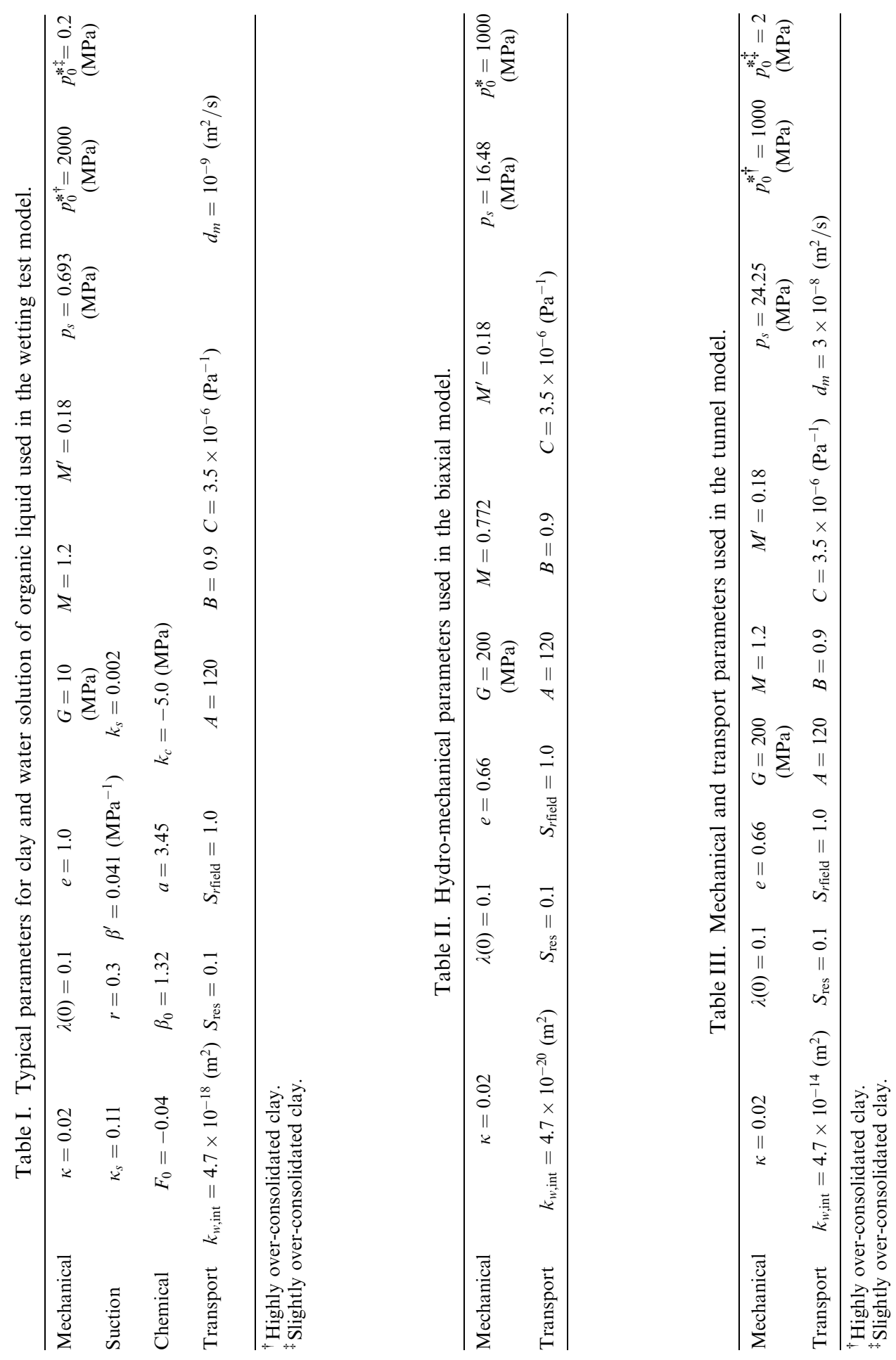

Copyright (C) 2005 John Wiley \& Sons, Ltd. Int. J. Numer. Anal. Meth. Geomech. (in press) 


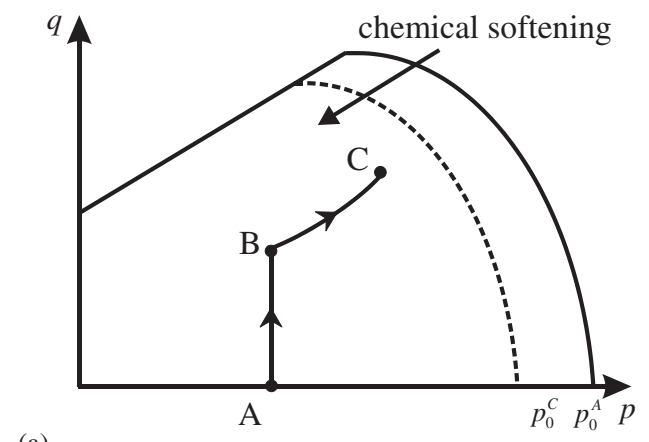

(a)
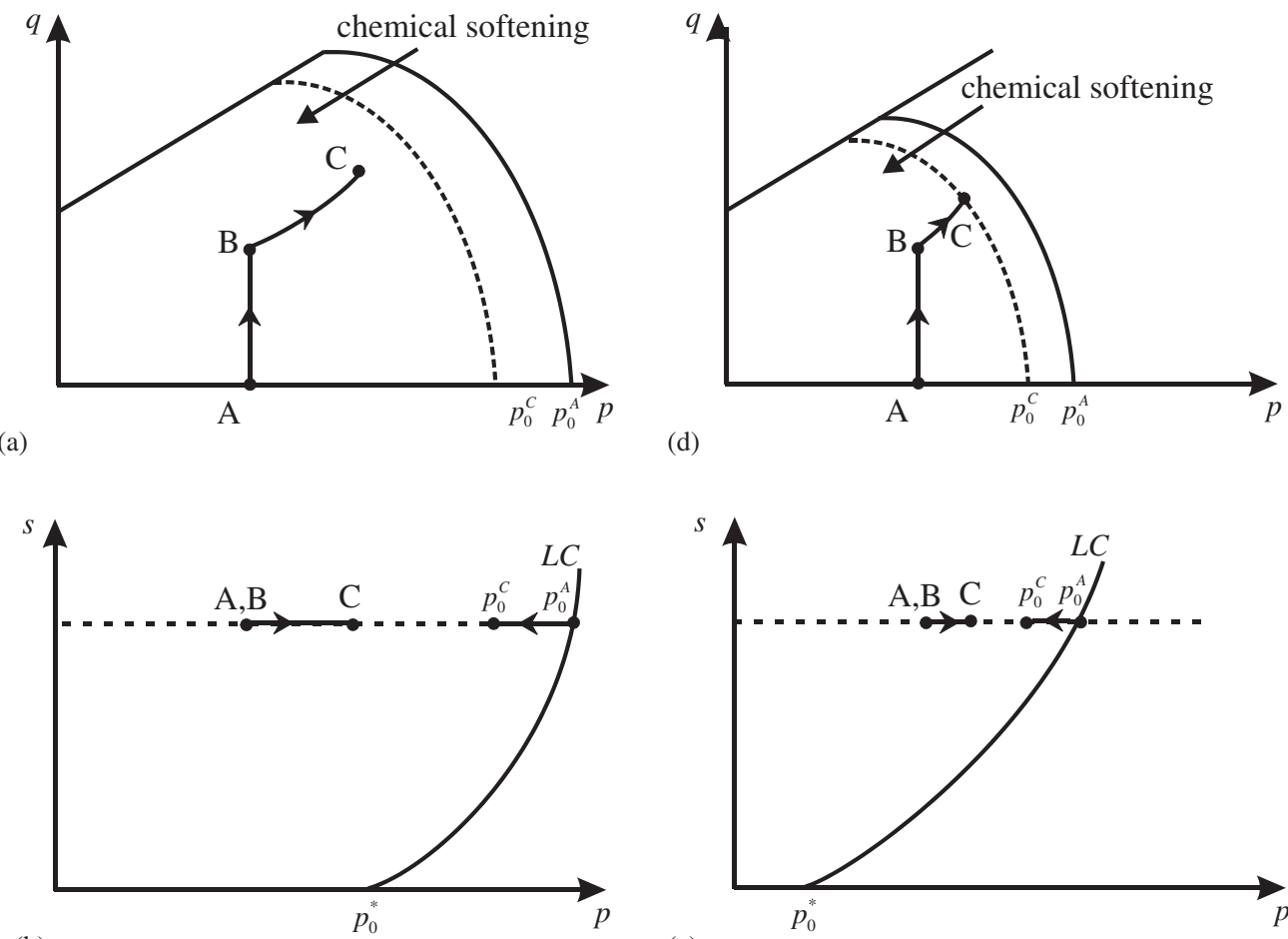

(b)
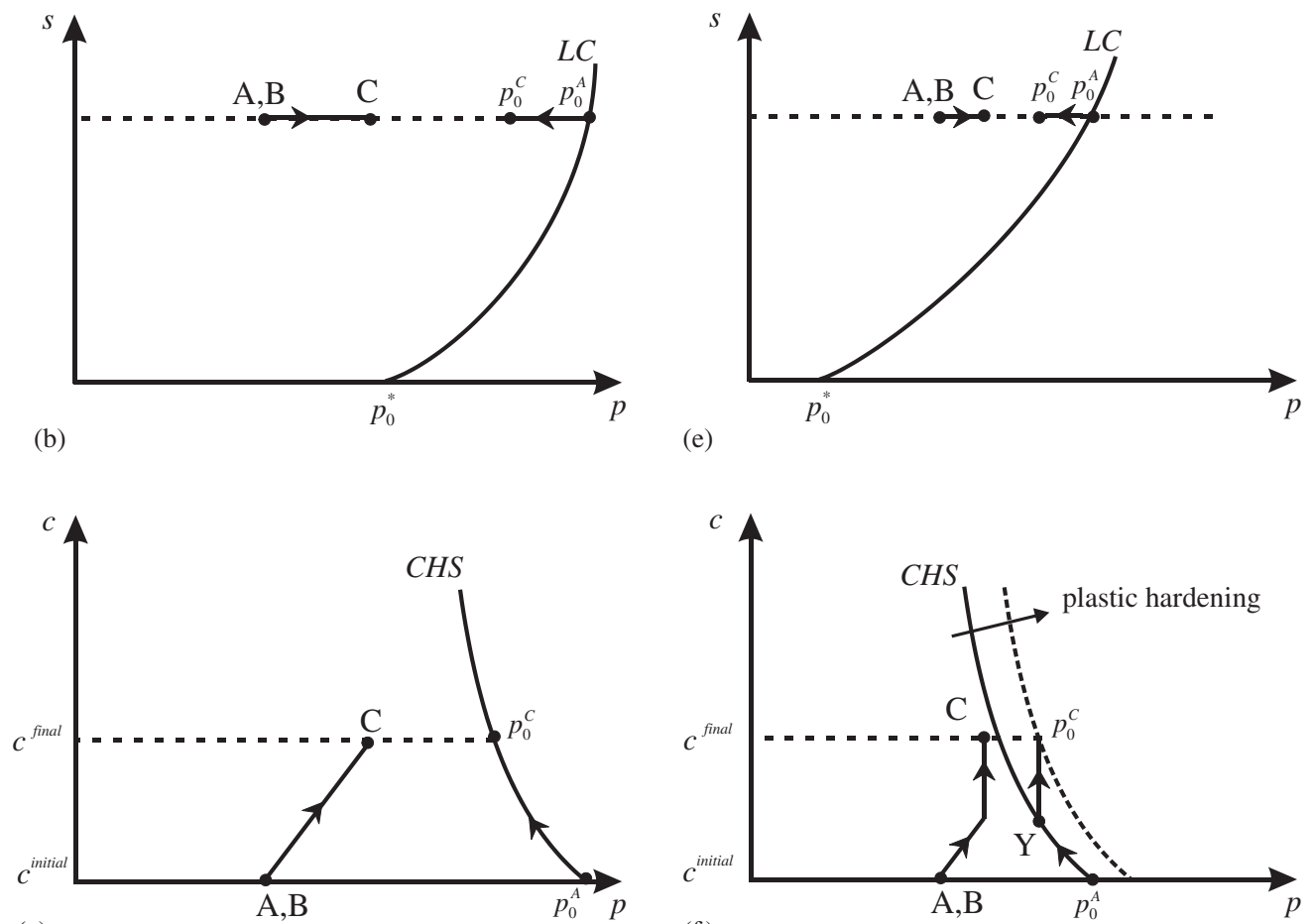

(c)

(e)

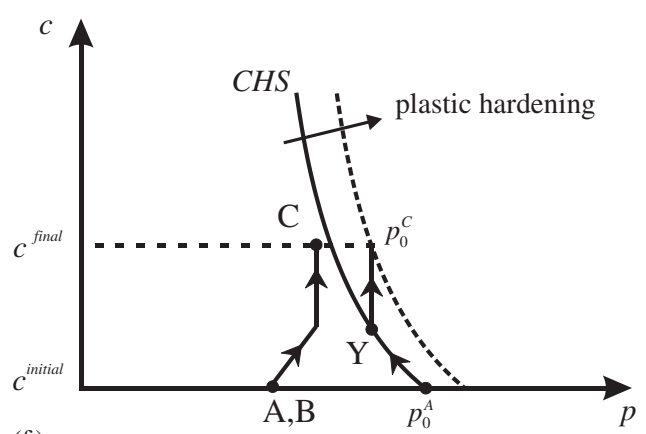

(f)

Figure 13. Loading path and evolution of $p_{0}$; for elastic response: (a) plane $(q, p)$; (b) plane $(s, p)$; (c) plane $(c, p)$; for elasto-plastic response: (d) plane $(q, p)$; (e) plane $(s, p)$; and (f) plane $(c, p)$.

after plastic yielding, and their variation depends on the relative strength of the chemical softening and plastic hardening mechanisms.

Let us consider the chemo-mechanical behaviour of the clay after a time $t=3 \times 10^{8} \mathrm{~s}$. At that time, fresh water has penetrated into the soil over a distance of approximately $10 \mathrm{~m}$ due to molecular diffusion, as depicted in Figure 14, where $r$ represents the radial distance to the tunnel's boundary. The distributions of strains and stresses with respect to $r$ are depicted in Figures 15 and 16. These distributions are quite axisymmetrical in the region around the tunnel 


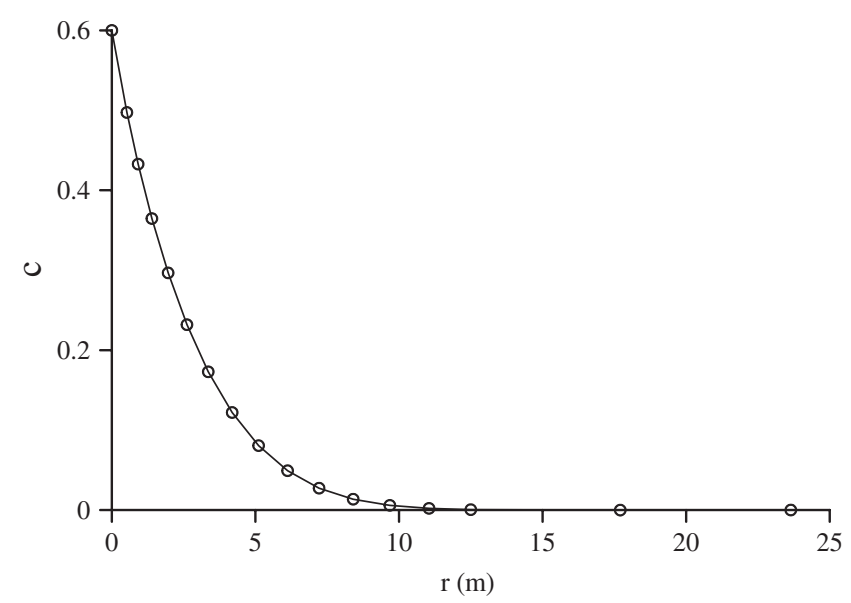

Figure 14. Distribution of chemical concentration with respect to the radial distance to the tunnel's boundary at time $t=3 \times 10^{8} \mathrm{~s}$.

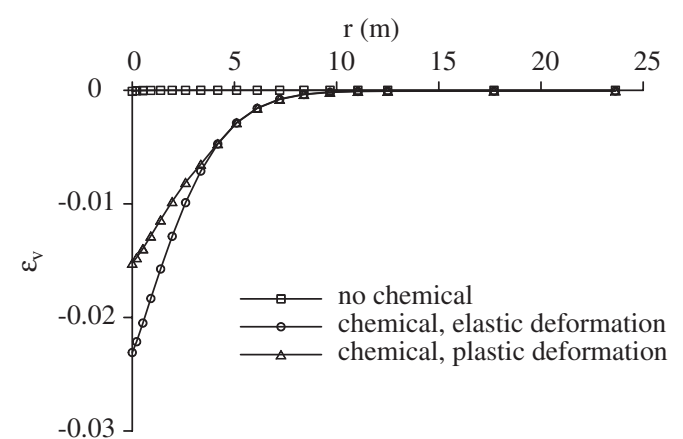

(a)

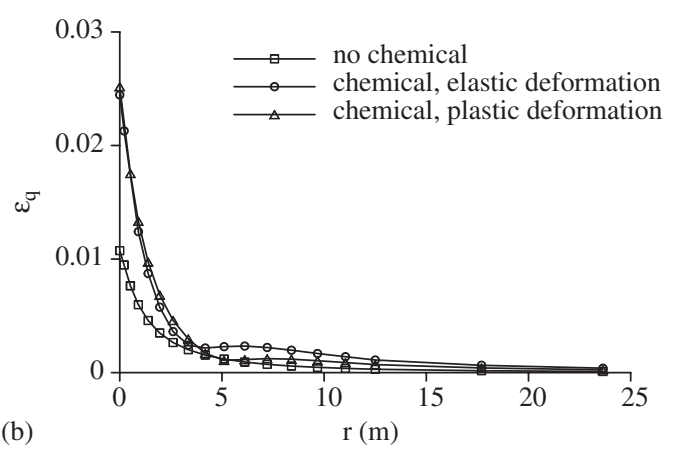

(b)

Figure 15. Distribution of strains with respect to the radial distance to the tunnel's boundary at time $t=3 \times 10^{8}$ s: (a) volumetric strain; and (b) deviatoric strain.

subjected to chemical effects of fresh water. In fact, the influence of the variation of in situ stresses due to gravity is negligible on the resulting stress and strain distributions.

Figure 15(a) indicates that chemical effects induce an expansion of the clay, whereas in the absence of chemical the excavation takes place without any volume change, as predicted by the elastic solution. The total clay expansion is reduced by the chemical plastic compaction taking place around the tunnel in the case of $p_{0}^{*}=2 \mathrm{MPa}$. Regarding shear strains, the chemical effects are quite similar in both cases, inducing a significant increase of shear strains close to the tunnel (Figure 15(b)). The tendency of the soil to expand due to chemical effects of fresh water results in an increase of the isotropic stress $p$ in the region around the tunnel, as shown in Figure 16(a). In the case where plastic compaction takes place, the increase of $p$ due to chemical effects is smaller, and its maximum value is reached at some distance of the tunnel's boundary. Similarly, an increase in the shear stress in the region close to the tunnel is observed due to the presence of the chemical, with a smaller effect in the case of plastic deformation (see Figure 16(b)). 

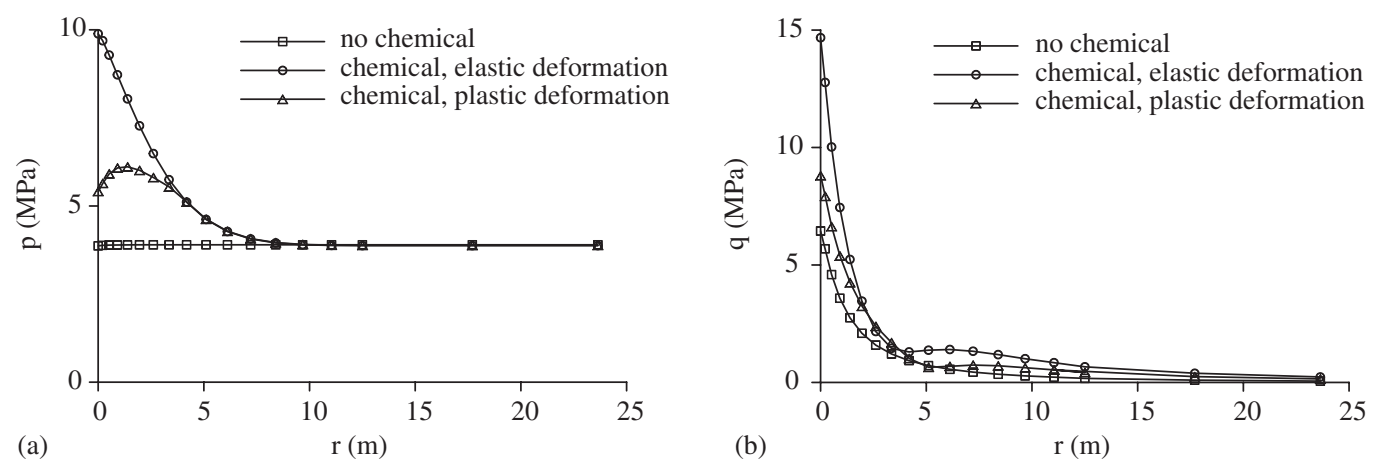

Figure 16. Distribution of stresses with respect to the radial distance to the tunnel's boundary at time $t=3 \times 10^{8} \mathrm{~s}$ : (a) isotropic stress; and (b) deviatoric stress.

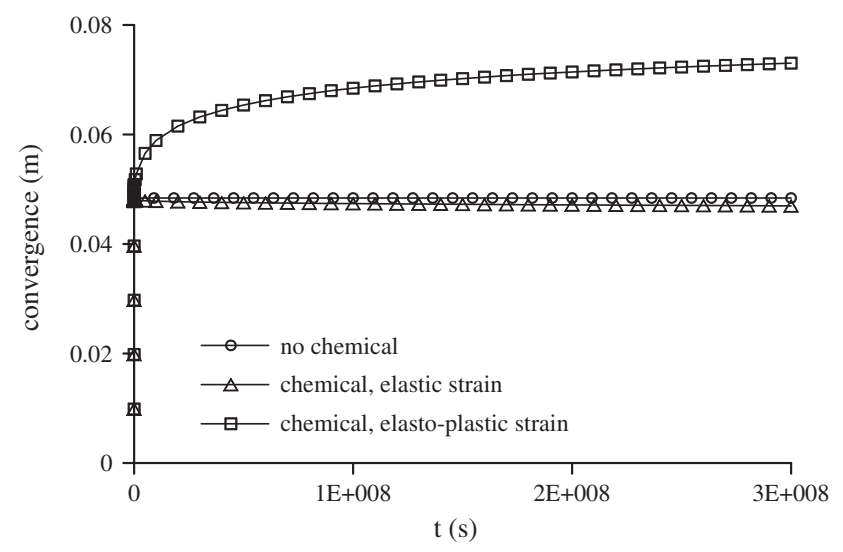

Figure 17. Chemical effects on the tunnel convergence.

Chemical effects of fresh water on the tunnel convergence are depicted in Figure 17. The convergence is calculated as the relative displacement of the highest and lowest point of the tunnel boundary. The convergence of the tunnel in the case of a purely mechanical elastic response is represented by the circles and coincides with the solution of Lamé. In the case of a chemo-elastic expansive behaviour, the chemical effects induce a small reduction in the convergence. In the case where the chemo-mechanical behaviour is elasto-plastic, with the plastic component of strain being contractive, the convergence of the tunnel is significantly larger than in the absence of chemical. Note that the difference between the convergence in the vertical and the horizontal direction is very small.

\section{CLOSING REMARKS}

The chemo-hydro-mechanical (CHM) model for unsaturated soil presented in this paper is based on the formulation of Collin [13] and on the concept of chemical softening proposed by 
Hueckel [7]. To model chemical degradation of strength properties, a new mechanism of chemical softening is introduced as a linear decrease of the cohesion with concentration. The constitutive model has been implemented in a numerical code, which has been adapted in order to solve coupled CHM problems. Three numerical benchmarks have been discussed, which demonstrate the capabilities of the model. In the first example of wetting of a clay specimen with a chemical, the significant deformation of the specimen is the result of the combined effects of the variations of suction and chemical concentration. The biaxial compression test example illustrates the possible risk of strength reduction due to chemical contamination. The last example demonstrates that chemical effects, due to contamination of clay rock by fresh water during excavation, can lead to unexpected tunnel convergence and stress distributions around the tunnel.

In the three cases considered, it appears clearly that all four principal mechanisms activated by variation in suction or in chemical content of the pore fluid play an important role in generating substantial strains in the soil, or, if constrained, stresses of the order of those normally induced by mechanical load. It is also concluded that history of environmental load plays an important role in generating response and needs to be clearly articulated in the formulation of the problem, when possible explicitly. Time dependence of the mechanical response, as introduced implicitly via coupling to advection or diffusion, is also seen to affect the history dependence.

To the authors' knowledge, no experiments have been reported, which investigate the combined effects of variations of suction and chemical concentration. The proposed model may be a useful tool in designing this type of experiment, or as a matter of fact, field studies. With regard to modelling the effects of chemical strength reduction, an effort is undertaken to compare the modelling results with available data and refine the model if necessary.

\section{APPENDIX A}

To derive the general form of the constitutive equations one rewrites the elastic relation (5) as

$$
\dot{\sigma}_{k l}=C_{k l i j}^{e}\left(\dot{\varepsilon}_{i j}-h_{i j}^{e} \dot{s}-l_{i j}^{e} \dot{c}-\dot{\Lambda}^{p} \frac{\partial g}{\partial \sigma_{i j}}\right)
$$

The plastic multiplier $\dot{\Lambda}^{p}$ is obtained by introducing the elastic relation and the hardening law (12) in the consistency condition (11)

$$
\dot{\Lambda}^{p}=\frac{1}{K_{p}}\left[\frac{\partial f}{\partial \sigma_{k l}} C_{k l i j}^{e} \dot{c}_{i j}-\frac{\partial f}{\partial \sigma_{k l}} C_{k l i j}^{e}\left(h_{i j}^{e} \dot{s}+l_{i j}^{e} \dot{c}\right)+\left(\frac{\partial f}{\partial \theta} \frac{\partial \theta}{\partial s}\right) \dot{s}+\left(\frac{\partial f}{\partial \theta} \frac{\partial \theta}{\partial c}\right) \dot{c}\right]
$$

where

$$
K_{p}=\frac{\partial f}{\partial \sigma_{k l}} C_{k l i j}^{e} \frac{\partial g}{\partial \sigma_{i j}}+H, \quad H=-\left(\frac{\partial f}{\partial \theta} \frac{\partial \theta}{\partial \varepsilon^{p}}\right) \frac{\partial g}{\partial \sigma_{i j}}
$$

Finally, the constitutive equation can be written in the following form:

$$
\dot{\sigma}_{k l}=\left(C_{k l i j}^{e}-C_{k l i j}^{p}\right) \dot{\varepsilon}_{i j}-M_{k l} \dot{s}-N_{k l} \dot{c}
$$




\section{MODELLING CHEMO-HYDRO-MECHANICAL BEHAVIOUR}

where

$$
\begin{gathered}
C_{k l i j}^{p}=\frac{1}{K_{p}} C_{k l r s}^{e} \frac{\partial g}{\partial \sigma_{r s}} \frac{\partial f}{\partial \sigma_{m n}} C_{m n i j}^{e} \\
M_{k l}=C_{k l r s}^{e} h_{r s}^{e}+C_{k l r s}^{e} \frac{\partial g}{\partial \sigma_{r s}} \frac{1}{K_{p}}\left(\frac{\partial f}{\partial \theta} \frac{\partial \theta}{\partial s}-\frac{\partial f}{\partial \sigma_{m n}} C_{m n p q}^{e} h_{p q}^{e}\right) \\
N_{k l}=C_{k l r s}^{e} l_{r s}^{e}+C_{k l r s}^{e} \frac{\partial g}{\partial \sigma_{r s}} \frac{1}{K_{p}}\left(\frac{\partial f}{\partial \theta} \frac{\partial \theta}{\partial c}-\frac{\partial f}{\partial \sigma_{m n}} C_{m n p q}^{e} l_{p q}^{e}\right)
\end{gathered}
$$

\section{ACKNOWLEDGEMENTS}

This work is sponsored by the Ministry of Education of Belgium under the international joint research project 'Qualité et durabilité de la protection des nappes aquifères sous sites d'enfouissement technique avec barrières argileuses d'étanchéité', the ARC No. 99/04-243, a scholarship from Fonds National de la Recherche Scientifique of Belgium (T.H.), and The National Natural Science Foundation of China under the projects No. 50278012 and No. 59878009. These supports are greatly acknowledged.

\section{REFERENCES}

1. Fernandez F, Quigley RM. Controlling the destructive effect of clay-organic liquid interactions by application of effective stresses. Canadian Geotechnical Journal 1991; 28:388-398.

2. Di Maio C. Exposure of bentonite to salt solution: osmotic and mechanical effects. Géotechnique 1996; 46(4): 695-707.

3. Olson RE. Shearing strength of kaolinite, illite and montmorillonite. Journal of Geotechnical Engineering, Proceedings of the ASCE 1974; 100(GT 11):1215-1229.

4. Mitchell JK. Fundamentals of Soil Behaviour. Wiley: New York, 1993.

5. Hueckel T. Water-mineral interaction in hygro-mechanics of clays exposed to environmental loads: a mixture approach. Canadian Geotechnical Journal 1992; 29:1071-1086.

6. Hueckel T, Loret B, Gajo A. Swelling clays as reactive deformable, two-phase materials: basic concepts and options. In Chemo-mechanical Coupling in Clays, Di Maio C, Loret B, Hueckel T (eds). Balkema: Rotterdam, 2002; 105-120.

7. Hueckel T. Chemo-plasticity of clays subjected to stress and flow of a single contaminant. International Journal for Numerical and Analytical Methods in Geomechanics 1997; 21:43-72.

8. Nova R, Castellanza R, Tamagnini C. A constitutive model for bonded geomaterials subject to mechanical and/or chemical degradation. International Journal for Numerical and Analytical Methods in Geomechanics 2003; 27: $705-732$.

9. Guimaraes L do N, Gens A, Sanchez M, Olivella S. Chemo-mechanical modelling of expansive clays. 6th International Workshop on Key Issues on Waste Isolation Research, Paris, 2001.

10. Olivella S, Gens A. A constitutive model for crushed salt. International Journal for Numerical and Analytical Methods in Geomechanics 2002; 26(7):719-746.

11. Boukpeti N, Charlier R, Hueckel T. Modelling contamination of clays. VII International Conference on Computational Plasticity, Owen DRJ, Onate E, Suarez B (eds), Barcelona, 2003.

12. Loret B, Hueckel T, Gajo A. Chemo-mechanical coupling in saturated porous media: elasto-plastic behaviour of homoionic expansive clays. International Journal of Solids and Structures 2002; 39:2773-2806.

13. Collin F. Couplages thermo-hydro-mécaniques dans les sols et les roches tendres partiellement saturés. Thèse de doctorat, de l'Université de Liège, 2003.

14. Collin F, Cui YJ, Schroeder C, Charlier R. Mechanical behaviour of Lixhe chalk partly saturated by oil and water: experiment and modelling. International Journal of Numerical and Analytical Methods in Geomechanics 2002; 26: 897-924.

15. Alonso EE, Gens A, Josa A. A constitutive model for partially saturated soils. Géotechnique 1990; 40(3):405-430. 
16. Gens A, Alonso EE. A framework for the behaviour of unsaturated expansive clays. Canadian Geotechnical Journal 1992; 29:1013-1032.

17. Charlier R. Approche unifiée de quelques problèmes non-linéaires de mécanique des milieux continus par la méthode des éléments finis. Thèse de doctorat, de l'Université de Liège, 1987.

18. Van Eekelen HAM. Isotropic yield surfaces in three dimensions for use in soil mechanics. International Journal for Numerical and Analytical Methods in Geomechanics 1980; 4:98-101.

19. Brooks RH, Corey AT. Hydraulic properties of porous media. Hydrology Paper No. 3, Colorado State University, 1964.

20. Vauclin M, Touma J, Wierenga P, Vachaud G. Comparison entre différents schémas de résolution numérique de l'équation de l'infiltration. Letters in Heat and Mass Transfer 1976; 2(6):473-479.

21. Radu J-P, Biver P, Charlier R, Cescotto S. 2D and 3D finite element modelling of miscible pollutant transport in groundwater, below the unsaturated zone. International Conference on Hydrodynamics, Wuxi, China, 1994.

22. Li X, Cescotto S, Thomas HR. Finite element method for contaminant transport in unsaturated soils. Journal of Hydrologic Engineering (ASCE) 1999; 4(3):265-274.

23. Steiner W. Swelling rock in tunnels: rock characterization, effect of horizontal stresses and construction procedures. International Journal of Rock Mechanics and Mining Science and Geomechanics Abstracts 1993; 30(4):361-380. 